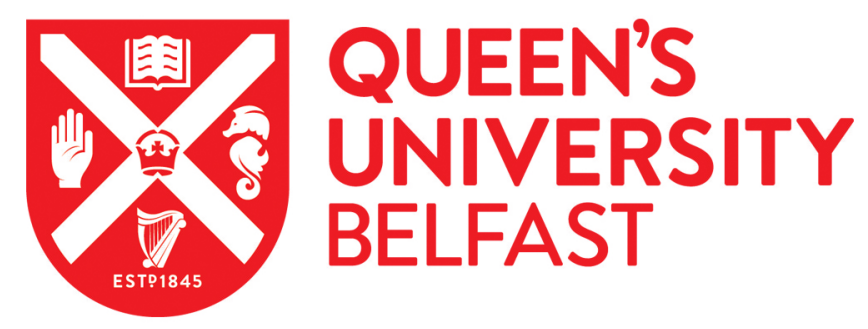

\title{
Tip Leakage Flow and Heat Transfer on Turbine Stage Tip and Casing: Effect of Unsteady Stator-Rotor Interactions
}

Rahman, M. H., Kim, S. I., \& Hassan, I. (2014). Tip Leakage Flow and Heat Transfer on Turbine Stage Tip and Casing: Effect of Unsteady Stator-Rotor Interactions. International Journal of Computational Methods, 11(4), [1350058]. https://doi.org/10.1142/S0219876213500588

Published in:

International Journal of Computational Methods

Document Version:

Peer reviewed version

Queen's University Belfast - Research Portal:

Link to publication record in Queen's University Belfast Research Portal

Publisher rights

(C) 2015 World Scientific Publishing Co Pte Ltd.

This work is made available online in accordance with the publisher's policies. Please refer to any applicable terms of use of the publisher.

\section{General rights}

Copyright for the publications made accessible via the Queen's University Belfast Research Portal is retained by the author(s) and / or other copyright owners and it is a condition of accessing these publications that users recognise and abide by the legal requirements associated with these rights.

Take down policy

The Research Portal is Queen's institutional repository that provides access to Queen's research output. Every effort has been made to ensure that content in the Research Portal does not infringe any person's rights, or applicable UK laws. If you discover content in the Research Portal that you believe breaches copyright or violates any law, please contact openaccess@qub.ac.uk. 


\title{
Tip Leakage Flow and Heat Transfer on Turbine Stage Tip and Casing: Effect of Unsteady Stator Rotor Interactions
}

\author{
Md Hamidur Rahman ${ }^{1}$, Sung In Kim ${ }^{2}$ and Ibrahim Hassan ${ }^{3}$ \\ Concordia University, Montreal, Quebec, H3G 1M8, Canada
}

\begin{abstract}
Unsteady simulations were performed to investigate time dependent behaviors of the leakage flow structures and heat transfer on the rotor blade tip and casing in a single stage gas turbine engine. This paper mainly illustrates the unsteady nature of the leakage flow and heat transfer, particularly, that caused by the stator-rotor interactions. In order to obtain time-accurate results, the effects of varying the number of time steps, sub iterations, and the number of vane passing periods was firstly examined. The effect of tip clearance height and rotor speeds was also examined. The results showed periodic patterns of the tip leakage flow and heat transfer rate distribution for each vane passing. The relative position of the vane and vane trailing edge shock with respect to time alters the flow conditions in the rotor domain, and results in significant variations in the tip leakage flow structures and heat transfer rate distributions. It is observed that the trailing edge shock phenomenon results in a critical heat transfer region on the blade tip and casing. Consequently, the turbine blade tip and casing are subjected to large fluctuations of Nusselt number (about $\mathrm{Nu}=2000$ to 6000 and about $\mathrm{Nu}=1000$ to 10000 , respectively) at a high frequency (coinciding with the rotor speed).
\end{abstract}

\section{Nomenclature}

$C=$ chord at the blade tip, $\mathrm{m}$

$C_{x}=$ axial chord at the blade tip, $\mathrm{m}$

$h=$ heat transfer coefficient, $\left(h=\frac{q}{T_{w}-T_{o r, i n}}\right), \mathrm{W} / \mathrm{m}^{2} \mathrm{~K}$

\footnotetext{
${ }^{1}$ Department of Mechanical and Chemical Engineering, IUT, Board Bazar, Bangladesh

${ }^{2}$ School of Mechanical and Aerospace Engineering, Queen's University Belfast, UK

${ }^{3}$ Department of Mechanical and Industrial Engineering, Concordia University, ibrahimh@alcor.concordia.ca .
} 


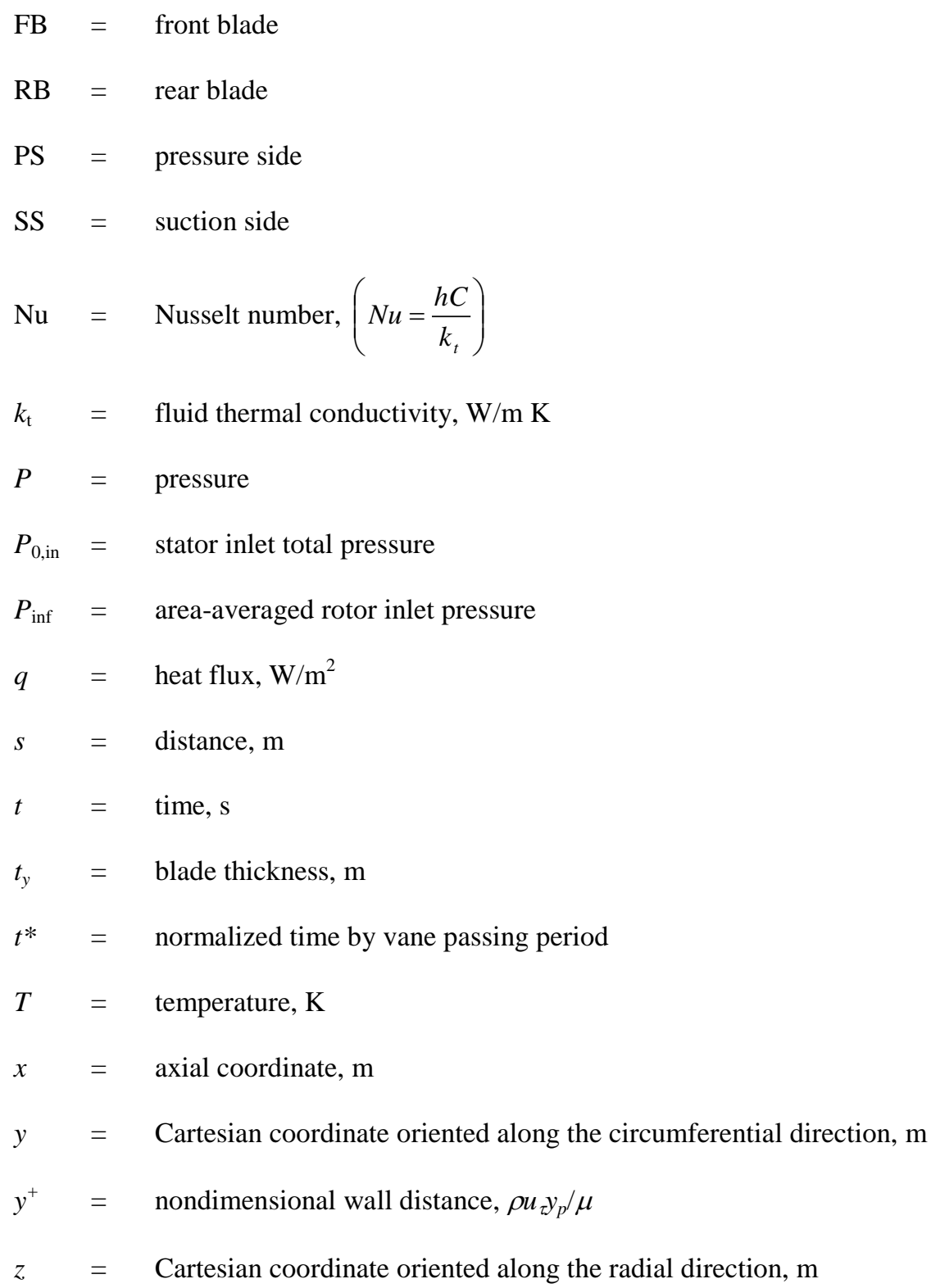

\section{Greek Symbols}

$$
\begin{aligned}
\Omega & =\text { rotor angular velocity, } \mathrm{RPM} \\
\rho & =\text { density, } \mathrm{kg} / \mathrm{m}^{3} \\
\theta & =\text { stator passing period, } \mathrm{s} \\
\varphi & =\text { stator angular pitch, } \mathrm{rad}
\end{aligned}
$$




Subscript
$\mathrm{w}=$ wall condition
$\mathrm{o}=$ total
$\mathrm{r}=$ rotor
in $\quad=$ inlet

\section{Introduction}

JNSTEADY analysis of the flow and heat transfer characteristics has been a leading research interest in gas turbine applications. Aerodynamics inside the gas turbine engine is highly unsteady due to the periodic movement of the rotor, wake and secondary vortical flows, and stator-rotor interactions. Moreover, these phenomena cause the heat transfer inside the turbine stage to be intensively time dependent. In gas turbine engines, the rotor tip clearance is one of the most critical regions and still presents major challenges to designers and engineers in the aerospace and power industries, since only few works have been devoted to attaining reliable and sufficient experimental data in this region.

Metzger et al. (1991) numerically investigated tip leakage flow and heat flux characteristics on the casing of the Garrett TFE 731-2 blades using an in-house Navier-Stokes code. A grid of $30 \times 7 \times 102$ was used inside the clearance region for a gap of 0.025 inch. The numerical predictions were compared with the experimental data acquired from a full turbine stage with an operating rotor speed of 20,000 RPM. The periodic fluctuations of the time resolved pressure and heat flux were reported. It was observed that the pressure fluctuations were strongly influenced by the casing heat flux.

Recently, the turbine blade tip and casing heat transfer characteristics in a rotating cascade were investigated. Yamamoto et al. (1994) studied the unsteadiness of the flows and associated losses in the blade tip clearance region. Their test facility consisted of a one and a half stage, low speed axial turbine with a blade tip clearance of $1.2 \mathrm{~mm}$. Random fluctuations of the flow were observed inside the tip clearance causing higher turbine stage losses. The region where the leakage flow separates from the blade tip showed unsteady behavior. Stator and Rotor interactions contributed significantly to the unsteadiness and complexity of the leakage flow structure.

The transport factors of the unsteady flow were investigated by Denos et al. (2006) in a transonic turbine stage both experimentally, and numerically, using an in-house computational fluid dynamics (CFD) code. The turbine stage comprising 43 vanes and 64 blades, was designed to operate at a pressure ratio of 3 and a speed of 6500 RPM. 
The fluctuations of the flow properties were reported to be higher at a higher Mach number than at subsonic conditions. The largest variations in the flow field were associated with a shock that originated in the stator section and propagated into the rotor section along with the flow.

The effect of stator-rotor interactions was investigated by Xie et al. (2007) for a 1.5 turbine stage numerically, using their in-house CFD code. The stage inlet pressure and temperature were specified as 7.3 bar and $536 \mathrm{~K}$, respectively. The rotor speed was set to 3000 RPM. The instantaneous pressure was monitored at the blade leading edge for three spanwise locations. The amplitude of the pressure fluctuations resulting from the upstream unsteady flow was observed to reach a maximum of 0.4 bars. The fluctuating force on the rotor blade indicated the effect of the separated vortices inherited by the upstream vane wake.

Phutthavong et al. (2008a, 2008b) performed both steady and unsteady simulations on a turbine stage model to investigate the blade tip leakage flow. An industrially owned CFD solver Nistar was used in their study. The shear stress transport (SST) $k-\omega$ turbulence model was selected in order to capture the flow characteristics in the tip gap region. It was observed that the shape and size of the flow separation on the tip surface varies with time.

Chana and Jones (2003) investigated experimentally the turbine tip and casing heat transfer in a high pressure light piston test facility. The turbine stage consisted of 32 vanes and 60 rotor blades. The experiments were carried out for a uniform inlet temperature of $444 \mathrm{~K}$, and non-uniform inlet temperature distributions ranging from $393 \mathrm{~K}$ to $470 \mathrm{~K}$. They captured the nature of the periodic pressure fluctuations by direct measurement on the rotor casing. Three distinct regions of the high heat transfer rate on the casing were observed for the uniform inlet temperature case. Two of them were seen along the path of the unsteady vane wake, while the other high heat transfer regions coincided with the traveling shock wave that originated from the vane trailing edge.

Polanka et al. (2003) conducted a parametric heat transfer study on a turbine tip and shroud in a single stage high pressure rotating turbine test facility. They imposed a pressure of $450 \mathrm{kPa}$, a temperature of $480 \mathrm{~K}$, a Mach number of 0.08 and $1 \%$ turbulence intensity as boundary conditions at the inlet. A nominal tip clearance gap of $5 \%$ of the blade span was used. Very high heat transfer rates were measured on both the blade tip and the shroud reaching levels as high as those measured in the stagnation region of the $96.5 \%$ span. They investigated the effect of Reynolds number $\left(1.19 \times 10^{5}\right.$ to $\left.4.3 \times 10^{5}\right)$ and pressure ratio (2.75 to 3.09$)$. Lower Reynolds numbers reduced the heat load on the airfoil in all regions. Both the higher and lower pressure ratios resulted in higher Nusselt numbers on the blade tip, due to an increase in the driving temperature and the local separation, respectively. 
Thorpe et al. (2005) obtained unsteady heat transfer and aerodynamic data in a transonic turbine stage test facility. They particularly studied the effect of stator-rotor interactions on the unsteadiness of the heat transfer along the blade tip mean camber line. A total of 36 nozzle guide vanes and 60 rotor blades were used at the design speed of 8910 RPM. A new thin film gauge fabrication technique was implemented to measure time resolved heat transfer rates. Three distinct heat transfer zones on the blade tip were identified each having different unsteady heat transfer characteristics; the blade-nose, mid-axial chord, and aft (downstream of the passage throat). The driving mechanisms of the unsteady heat transfer, namely, the tip leakage flow fluctuations, relative total temperature fluctuations, and vane-shock interactions were described. It was also reported that the relative total temperature fluctuations are influenced by the static pressure fluctuations.

Molter et al. (2006) conducted both numerical and experimental investigations on rotor tip aerodynamics and heat transfer. They used a commercial CFD solver STAR-CD for the numerical computations and compared the predictions with the measured data. Experimentally, they observed that heat load at the blade tip is about $25 \%$ higher than that recorded at $90 \%$ span. Their measurement also showed significant unsteady variations in the heat load on the blade tip at the vane passing frequency. The steady numerical simulations couldn't capture the heat load variations, indicating that the stator interacts strongly with the rotor flow field and causes unsteadiness of the flow and heat transfer in the rotor domain. Therefore, time accurate analysis of a full turbine stage is necessary to fully understand the flow and heat transfer characteristics in the rotor tip clearance region.

De la Loma et al. (2007) investigated the effects of a strong shock on the heat transfer distribution in a transonic turbine stage. The turbine stage comprised 43 uncooled vanes and 64 blades and the experiment was conducted in the compression tube turbine test facility. The experiments were performed for maximum isentropic Mach numbers ranging between 1.07 and 1.25 . The data were presented at three span locations (15\%, 50\%, and $85 \%)$ of the blade and at the mid span of the vane. It was reported that the unsteady heat transfer on the front of the blade is mostly induced by the impinging shock that originated in the stator section. The instantaneous heat flux in the rotor crown was twice the time-averaged values due to the strong shock interactions between blade rows.

Krishnababu et al. (2009a, 2009b) investigated the effect of tip geometry in part 1 and effect of relative casing motion on the tip leakage flow and heat transfer characteristics in a single blade axial flow turbine. They performed numerical study using CFX 5.6 computational software. The structured grid was generated using ICEM-HEXA software. Three tip geometries used are flat tip, cavity tip, and suction side squealer tip. The results are presented for 
two tip gap heights of $1.6 \% \mathrm{C}$ and $2.8 \% \mathrm{C}$. SST $k-\omega$ based turbulence model was employed for turbulence closure. Their computational results were compared with the experiment and found $5-10 \%$ underprediction in average heat transfer at the tip. They also found that the flow is separated to a larger extend in compared to the experimental results. Their results revealed that in provision of two tip geometries, cavity tip could reduce the leakage mass flow, whereas for suction side squealer tip it is increased. On the other hand, average heat transfer was decreased for both cavity and squealer tip in compared to flat tip. In another study, the effects of all three tip geometries were investigated. In this study, they found that relative casing motion can increase the average heat transfer than stationary casing for all tip geometries. It was also concluded that relative motion of the casing is computationally expensive to consider in regard to the ranking of tip geometries than the stationary casing.

Yang et al. (2010) investigated the effect of rotation on the leakage flow and heat transfer at the blade tip. They performed steady simulation using CFD 5.7 CFD software. The computational grid was generated using ICEM CFD software. Low Reynolds number $k$ - $\omega$ model was employed as turbulence model. Investigations were made for three cases where blade domain is rotating and shroud is stationary, blade domain is stationary and shroud is rotating and both blade domain and shroud are stationary. They considered the influence of centrifugal force, Coriolis force and relative motion of the endwall. They concluded that relative casing motion can strongly effect on the tip leakage flow and heat transfer.

An unsteady analysis of tip and endwall heat transfer was conducted by Shyam et al. (2012). They performed numerical simulation using 3D unsteady code MSU-TURBO. For turbulence capture a low Reynolds number $k-\varepsilon$ model was employed. The height of the tip clearance investigated was $2.1 \%$ of the blade span. They concluded that the unsteadiness in the tip gap is due to inviscid effect of high speed flow. However, they found the pressure difference across the tip gap has no strong dependency. They also explained the work transfer phenomenon for the first time in the open literature.

Palafox et al. (2012) experiments a large scale turbine cascade with moving endwall for the analysis of blade tip heat transfer and aerodynamics. The Reynolds number of the flow was $4 \times 10^{5}$. The tip gap heights used for their study were $1 \%$ to $3 \%$ of the blade chord. The relative motion between the endwall and the blade tip was maintained by a moving belt. Their experimental result revealed that the average Nusselt number on the tip surface can reduce upto $13.3 \%$ due to relative motion of the moving wall. Addition of suction side squealer tip could also reduce the average Nusselt number by $32 \%$. 
From the above literature, the following key points could be summarized:

- Pressure fluctuations are significant at the inlet and outlet of the blade tip gap.

- The size and shape of the separated flow varies with time due to upstream unsteady flow.

- The periodic passing of the rotor causes pressure fluctuations of several orders of magnitude.

- Progressing shock waves enhance blade tip heat transfer and cause large variations in the flow field.

- A critical region of high heat transfer is located on the camber line of the blade tip section. However, it varies depending on the rotor tip characteristic parameters.

- Due to endwall motion both heat transfer and leakage flow on the tip is influenced.

In the earlier studies (Rahman et al., 2010, 2012, 2013; Kim et al. 2012), grid sensitivity and validations and steady analysis of tip leakage flow structures and heat transfer distributions have been investigated. Also, the effect of tip clearance heights and rotor speeds on tip leakage flow and heat transfer rate was systematically analyzed. However, the flow physics inside the turbine tip is proven to be highly unsteady, three dimensional and complex; consequently the turbine blade tip and casing are characterized by the critical nature of the heat transfer occurring in that region. Based on the literature study, it is apparent that a complete gas turbine simulation in respect of the relative casing motion using different size of the tip gap, single stage but two rotor blades, high loaded stage are unnoticed. Therefore, further unsteady simulations resembling actual operating conditions are still required to account for the effect of stator-rotor interactions, progressive stator trailing edge shock, secondary flow and wakes, influence of flow around one blade onto another and periodic rotor-vane passing. Thereby, the objective of this study is to investigate the time dependent nature of the turbine blade tip and casing heat transfer associated with the unsteady complex tip leakage flow while taking into consideration the challenges coupled with achieving numerical time-accurate convergent solutions. The unsteady results of the tip leakage flow and heat transfer due to the statorrotor interaction have been discussed based on the numerical methodology to achieve the time-accurate solution.

\section{Computational Details}

In the present study, a single stage gas turbine engine was modeled and simulated using a commercial CFD solver ANSYS ${ }^{\circledR}$ CFX ${ }^{\circledR}$ R.11. The computational domain consists of one vane and two rotor blades (FB and RB), as shown in Fig. 1a. The grid was generated by using ANSYS $^{\circledR}$ ICEM CFD $^{\mathrm{TM}}$ grid generation tools. Unstructured tetrahedral grids were adopted (Fig. 1b) with appropriate grid resolutions in the tip clearance zone. High resolution second order central difference scheme for the space and second order backward Euler scheme for the time were 
used to discretize the equations for the flow, turbulent kinetic energy, and specific dissipation rate. Krishnababu et al. (2009a) compared the predictions of tip leakage flow and heat transfer using ANSYS CFX solver with turbulence models; $k-\omega, k-\varepsilon$, and SST $k-\omega$ models. It was found that SST $k-\omega$ model shows better agreement with experimental data. Thus, SST $k-\omega$ turbulence model was selected for turbulence closure in the present study. Boundary conditions based on the experimental works of Chana and Jones (2003) were applied (see Table 1). At the inlet of the stator domain, a total pressure of 4.6 bars and a total temperature of $444 \mathrm{~K}$ were specified, while a static pressure of 1.46 bar at the rotor domain outlet was set to achieve a value close to the experimental blade exit static pressure. Constant wall temperature boundary condition was applied on the surface. More details of the boundary conditions, computational domain, and grid system for the present methodology can be found in the earlier studies. Firstly, steady simulations were conducted using the ANSYS CFX 'Stage' option at the interface between the stator and rotor. The CFX "Stage" option for the interface performs a circumferential averaging of the fluxes at the stator outlet (upstream side of interface) and applies the averaged flow data as boundary conditions at the rotor inlet (downstream side of interface). Then, the converged steady solutions obtained via the "Stage" interface option were used as initial conditions to the time dependent simulations. Unsteady simulations were performed using 'Transient Rotor-Stator' interface option of ANSYS CFX. A sliding interface is used to allow rotational movement of the rotor domain with respect to stationary stator domain. A sufficient number of time steps were used to ensure that the flow field is adequately resolved for each vane pass. The time dependent heat transfer results were then recorded on the rotor blade tip and casing, and finally analyzed. The simulations case parameters are shown in Table 2.

\section{Tests for Time Step, Sub Iteration and Vane Pass}

The accuracy of the unsteady simulations is highly dependent on the number of time steps during one vane passing period (the time step size) and the number of sub-iterations in one time step. Optimum numbers of time steps and sub-iterations were selected after thorough trials and comparisons of results, allowing reductions in computational costs while achieving accurate solutions in time. Figure 2 illustrates the effect of the number of subiterations (Fig. 2a) and the number of time steps (Fig. 2b). In unsteady simulations, sub-iterations are required to achieve a converged solution in time increments. The number of sub-iterations selected allowed a three-order reduction in the residuals. Negligible differences were observed in v-velocity profiles in the tip gap obtained with 20 and 30 sub-iterations (Fig. 2a). On the contrary, a comparison of v-velocity profiles at $25 \%$ axial chord obtained with 20 and 40 time steps showed a maximum discrepancy of about $23 \%$ of the total v-velocity range $(-200 \mathrm{~m} / \mathrm{s}$ to 
$100 \mathrm{~m} / \mathrm{s}$ ) in the location marked A in Fig. 2b. However, increasing further the number of time steps to 60 resulted in velocity profiles extremely similar to those obtained with 40 time steps. Convergence of the continuity, momentum, heat transfer and turbulence equations was monitored during the simulations. It was observed that for each time step the target residuals were achieved within 20-25 sub iterations. It was also seen that after 4 vane passing periods the solutions were oscillating with negligible differences. Therefore, the simulations were performed for five vane passing periods with 20 sub-iterations and 40 time steps. Then, the simulations were run for one more vane passing period to record the unsteady data to be analyzed in the present study. All simulations were performed using a parallel computing system comprising 14 processors of $2.2 \mathrm{GHz}$ AMD Opteron each and 14 GB memory on the High Performance Computing cluster system at Concordia University. The simulation time was approximately 6 days for 6 vane passing periods.

\section{Results and Discussion}

\section{A. The Stator - Rotor Interaction}

The over-accelerated nozzle vane flow is accompanied with a shock at the stator trailing edge, in order to match the back pressure. The phenomenon of the stator trailing edge shock is usually encountered in a turbine stage; operating at transonic flow conditions. The trailing edge shock interacts with the blade passage flow resulting in a change in the flow momentum. The instantaneous pressure contour in the region between the stator and the rotor at the $75 \%$ blade span is depicted in Fig. 3, illustrating the effect of the upstream stator flow on the downstream rotor flow field. The compression wave (narrow band with relatively high pressure gradient) from the stator trailing edge can be seen in Fig. 3. The high pressure region behind the compression wave is progressing towards the rotor blade; it corresponds to the stator trailing edge shock. To accurately capture the shock wave phenomenon, fine grid adaptation is ideally used in the shock region, but was not implemented in the present study to avoid unacceptable long computational times. This study was focused on the tip clearance region in which fine mesh was adopted. Predicted results at various instants in time demonstrate that the rotor aerodynamics is greatly affected by the upstream stator flow structure. Hence, the pressure loading on the blade varies significantly with respect to time, furthermore affecting the leakage flow aerodynamics. At an instant in time, a relatively high pressure region can be seen on the pressure side of one blade with respect to the adjacent blade (Fig. 3). Similarly to the blade passage flow, the tip leakage flow is also greatly influenced by the flow structure in the stator domain. Steady CFD 
simulations did not capture the effect of the stator shock in the rotor domain mainly because of the averaging treatment at the stator-rotor interface.

To understand the interaction between the stator flow and the rotor flow, the velocity triangle and incidence angle are presented in Fig. 4a. Velocities $\mathrm{V}$ and $\mathrm{W}$ are the absolute and relative velocities, respectively. $\mathrm{V}_{\mathrm{bl}}$ is the rotational velocity of the rotor blade, $\mathrm{r} \omega$ (r=radius, $\omega=$ angular velocity). The superscripts " - ", " 0 ", and “+” indicate negative, zero and positive incidences, respectively. The incidence angle, $i$, is defined as $\left(\beta_{1}-\beta_{1}^{0}\right)$. It is to be noted that the rotor flow fields were observed through one pitch (12 degree) window in the stagnation frame. Figure 4 also presents the relative inlet flow angle $\left(\beta_{1}\right)$ variations along the circumferential direction at the mid tip clearance of the rotor side interface for two different rotation speeds. Inlet flow angles, $\beta_{1}$, were calculated using the relative velocity vectors of the axial and tangential components at the rotor inlet. Small inlet flow angle means that the rotor inlet flow direction is close to the axial direction. A positive inlet flow angle larger than the blade inlet angle, $\beta_{1}{ }^{0}$, indicates positive incidence. The time-dependent relative positions of the two adjacent blades also depicted in Fig. 4b. Typically, the circumferential variation of the rotor inlet flow angle is characterized by a saw tooth shape (periodic distribution), because the vane outlet velocity distribution shows a wave pattern resulting from the vane wake and boundary layer effects. In steady CFD simulations, a constant inlet flow angle was used because of the circumferential averaging at the interface. In Fig. 4 , the $\beta_{1}$ variation shows a wave pattern along the circumferential direction. The $\beta_{1}$ distribution varies with time, due to the interaction between stator and rotor. However, regardless of time, the inlet flow angle changes considerably in the fixed region, about 4-5 degrees pitch angle, as the flow passes the compression wave. The amplitudes of inlet flow angle variation at the rotor inlet are about \pm 17 and \pm 22 degrees (for 9500 RPM and 12500 RPM, respectively). Tip leakage flow structure is seen to vary with varying flow incidence depending on the position of the rotor relative to the stator at each instant in time. As the flow passes the compression wave, the inlet flow angle suddenly drops, thus, turning the inlet flow towards the axial direction. Then, the rotor inlet flow angle gradually increases. The overall inflow angle in Case 3 (Fig. 4c) is lower than the one in the low speed case. The maximum angle reached is about $50 \mathrm{deg}, 25$ degrees lower than the one of Baseline case (Fig. 4b). The blade tip region is covered by the blade loading driven tip leakage flow (BLL) from the pressure side when the rotor has a positive incidence angle (Baseline case, 9500 RPM). In this case, most of BLL has a direction normal to the blade profile of the pressure side edge. As a result, the separation bubble (SB) occurs along the pressure side edge. In contrast to Baseline, the suction side tip leakage from the leading edge incidence flow 
(SSL) mainly covers the upstream parts of the tip clearance region (near the leading edge) in Case 4 (15500 RPM; negative incidence). Therefore, SB near the pressure side edge becomes very small and not dominant up to $70 \%$ of axial chord.

\section{B. Time Periodic Patterns}

Typical flow structure taking place in the tip clearance region was sketched in Fig. 5a. The no slip condition on the blade tip and the constant relative motion of the casing in a direction opposite to that of the tip leakage flow create a complex tip clearance viscous flow field. Leakage flow entering the tip gap from the pressure side with sudden change in area and direction causes flow separation (SB) from the blade tip surface. Leakage flow then reattaches on the tip surface (LR) beyond SB. The outer casing velocity $\mathrm{V}_{\text {casing }}$ shears the outer edge of the tip leakage flow in the gap. It follows that there must be a stagnation line S1-S2 on which the velocity is zero. The relative flow (RR) with respect to the blade tip is reversed near the casing.

Time dependent variations of the flow field inside the tip clearance region were monitored for pressure, temperature and velocities, as presented in the Fig. 5. The time is normalized by one stator passing period of the rotor and formulated as

$$
\mathrm{t}^{*}=\frac{t}{\theta_{\text {stator }}}
$$

Where $\theta_{\text {stator }}$ is the one stator passing period of the rotor, that can be further calculated as

$$
\theta_{\text {stator }}=\frac{\varphi_{\text {stator }}}{\Omega}
$$

All monitoring points were located inside the tip clearance region of both the front blade (FB) and the rear blade (RB) at one quarter axial chord plane. The pressure is normalized using area-averaged rotor inlet pressure $\left(\mathrm{P}_{\text {inf }}\right)$ from the steady results. The wall heat flux is calculated using the monitored wall adjacent temperature and constant wall temperature. In Fig. 5, the periodic patterns of the flow field can be observed for both adjacent blades with a phase lag equal to half of the vane passing period. The amplitude of the pressure fluctuations is about $20 \%$ of the averaged rotor inlet pressure. When the monitoring point (at $y / t_{y}=50 \%$ on Tip) is in the separation zone of the leakage flow, lower pressure (A in Fig. 5b) is obtained. The leakage flow varies with time. The leakage flow reattachment (LR) results in higher pressure (B in Fig. 5b). Pressure variations on the blade tip indicate the unsteady nature of the leakage flow in the tip clearance region. The pressure is low in the separation zone and high when the tip leakage flow reattaches on the tip surface. The heat flux variations with respect to non-dimensional time are presented in 
Fig. 5c at two points to illustrate the effects of the relative reverse flow (RR) and LR. When the leakage flow reattaches on the tip surface, the boundary layer insulation becomes thin and thus, increases the wall heat flux (B in Fig. 5c). The maximum amplitude of the heat flux fluctuation on the blade tip, caused by the unsteady leakage flow variations, reaches up to about $50 \%$ of the mean heat flux on the blade tip. Therefore, the flow and heat flux fluctuations should be considered to understand the characteristics of the tip clearance region.

\section{Tip Leakage Flow Structural Variation}

The instantaneous tip leakage flow and heat transfer data were captured at eight instants in time at an equal time interval during each vane passing period. In one vane pitch (12 degree), there are two adjacent blades (FB and RB), showing the same periodic behaviors with half-period phase lag (see Fig. 5b). Thus, major features of one period can be seen during only half period time with two adjacent blades.

Leakage flow structures at different time instants are visualized using 2D velocity vectors in Fig. 6, for both the front and the rear blades (FB and $\mathrm{RB}$ ) at the quarter axial chord plane, in the tip clearance region for a rotating frame of reference. The variations of SB, LR and RR with time are evident in these vector diagrams. At each instant, the tip leakage flow structure is different for the two neighboring blades. The tip leakage flow variation follows the sequence of 1-4 (Fig. 6). Variations in the tip leakage flow structure can be attributed to the stator-rotor interactions. The vector flow-field shows that at the time instant, $t^{*}=4 / 8$, there is minimum interaction between $R R$ and the leakage flow in the rear blade (RB) region (blade 1). This is because the inlet flow angle is smallest and the pressure difference is highest between blade pressure and suction sides due to the compression wave from the stator (see Figs. $3 \& 4$ b). As a result, the leakage flow speed (which is mostly aligned with the axial direction and perpendicular to the RR direction) is highest over the RR in the tip region. As the blade rotates, the relative position of the blade with respect to the vane and the inlet flow angle change (Fig. 4). The leakage flow varies with time as shown in Fig. 6 from (1) to (4). When the rear blade (blade 4), at time $t^{*}=2 / 8$, is located just before the compression wave, the leakage flow inlet angle is highest and the pressure difference is lowest. The leakage flow encounters (almost opposite direction) the RR. As a result, the RR has significant coverage in the clearance region. The same typical leakage flow structure can be observed for other clearance heights as well (Fig. 6). It can be concluded that the leakage flow is characterized by its highly time dependent nature with variations in SB and RR coverage.

The tangential component of the velocity in the clearance region is considered to illustrate the effect of the opposing movements of the leakage flow and the casing. In Fig. 7, the instantaneous tangential velocity distributions 
are plotted for both the front and rear blades against the normalized height of the tip gap at a location of $y / t_{y}=50 \%$ and $x / C_{x}=25 \%$. The instantaneous profiles are compared with time averaged and steady results. Figure 7 shows that the local tangential velocity reaches a maximum value of $250 \mathrm{~m} / \mathrm{s}$ near the casing, due to the variation in the balance between the leakage flow and RR. Also, it is noticeable that the flow direction changes with time near the tip surface, representing the variation of the SB zone. These leakage flow variations with time become more drastic as the tip clearance height increases. Steady prediction shows the typical velocity profile of the tip leakage flow. However, the steady profile is different from the instantaneous and time averaged profiles, particularly near the tip surface and casing where the unsteady variation is severe. The relation between these unsteady flow and the unsteady heat transfer characteristics on the tip surface and casing is to be discussed in the next section.

\section{Heat Transfer Rate Distribution Variation}

The unsteady heat transfer data were recorded on the rotor blade tip and casing and compared with the timeaveraged and the steady solutions. Figure 8 presents contours of the Nusselt number on the casing for the baseline case. The effect of the interaction between the RR of lower temperature and the tip leakage flow of higher temperature on the heat transfer rate distribution is evident. Due to variations in the balance between tip leakage flow and RR, the higher Nusselt number region moves back and forth circumferentially with a changing slope during one vane passing period. Figure 8 shows that the larger and higher Nusselt number regions occur over the front blade (B in Fig. 8) at $t^{*}=2 / 8$ and over the rear blade (A in Fig. 8) at $t^{*}=4 / 8$. The blades' leakage flow is characterized by the higher pressure difference between the blade sides due to the compression wave from stator (Fig. 3). The time averaged heat transfer rate distribution shows a smeared heat transfer rate between the high and low heat transfer regions due to the time averaging. The steady prediction gives a lower Nusselt number distribution because unsteady effects resulting from rotor stator interactions are neglected in steady-state CFD simulations. In summary, the stator trailing edge shock phenomenon results in a higher pressure difference between blade sides, thus, enhancing the tip leakage flow and producing severe heat transfer features.

Nusselt number distributions along the casing circumference at $25 \%$ axial chord are plotted in Fig. 9. The circumferential Nusselt number distribution is very steep; the maximum value of Nusselt number is located near the pressure side edge due to the high pressure and temperature of the tip leakage flow. The heat transfer rate is lowest near the suction side edge. The casing is subjected to large variations in Nusselt number ranging from around 1,000 up to around 10,000. The higher pressure and temperature leakage flow that is located near the blade pressure side 
and the blade leading edge, and caused by the compression wave, induces a higher heat transfer rate instantaneously. The instantaneous peak value of heat transfer rate is about $17 \%$ and $40 \%$ greater than the time-averaged and steady peaks, respectively. As a result, the thermal stresses are expected to be higher which could cause severe consequences to the casing metal. The casing should be able to sustain this large heat flux fluctuation with high frequency $(9.5 \mathrm{kHz}$ for the baseline case). The pattern of heat transfer rate distribution captured by the steady predictions shows good agreement with the time-averaged data. However, steady simulation seem to underpredicted the maximum Nusselt number and could not provide information illustrating heat fluctuations.

Figure 10 shows the Nusselt number distributions on the blade tip surface at different time instants, the time averaged and steady predictions. The local Nusselt number distributions on the blade tip at the $25 \%$ axial chord plane are also plotted in Fig. 12. The low and high heat transfer regions on the tip surface are strongly related to the SB and LR. The size and location of the SB and LR are affected by the flow incidence angle and the blade loading. Along the leakage flow passage from pressure to suction sides, the typical heat transfer distribution on the tip surface can be seen for blade 2, 3, and 4 in Fig. 10 and RB at $t^{*}=1 / 8, F B$ and RB at $t^{*}=3 / 8$ in Fig. 11; low heat transfer rate near pressure side by SB, high heat transfer rate by LR, and heat transfer rate decreasing again by the secondary reversed leakage vortex (SRLV), a vortical mixing between the tip leakage flow and RR (Rahman et al. 2010). The inlet flow angle (indicated by an arrow in Fig. 10) increases with the sequence of 2-3-4, thus, the high heat transfer region, caused by the LR, moves normal to the leakage flow direction. However, blade 1 in Fig. 10 and FB at $t^{*}=1 / 8$ in Fig. 13, have the smallest inlet flow angle (close to axial direction) and the highest pressure difference due to the compression wave from stator (Fig. 3). At this instant in time, the effect of the RR was seen to be the lowest (Fig. 6) due to high speed leakage flow. As a result, Nusselt number gradually increases toward the suction side. Although the instantaneous heat transfer rate distributions are different for each blade, they are almost the same for both blades after time averaging. This indicates the periodic characteristics of the unsteady tip leakage flow and heat transfer rate. The steady heat transfer rate distribution exhibited a pattern that is similar to the time averaged one. The unsteady heat transfer rate distribution showed a locally and instantaneously higher heat transfer value; about $30 \%$ greater than steady prediction (Baseline case).

The contour of the Nusselt number on the rotor casing and tip surface is presented in Figs. 12 and 13 for Case 4. At a higher rotating speed, the high heat transfer rate regions were shifted to the mid chord along the pressure side edge due to the change in flow incidence. The effect of the stator flow structures on the local heat transfer rate 
becomes more severe at a higher rotation speed. A higher heat transfer rate region, illustrated by higher temperature and pressure, is observed on the casing (Fig. 12) and the tip surface (Fig 13), as the stator compression wave reaches the surfaces. The trace of the stator wake can be also seen in Fig. $12 \mathrm{~b}$.

Figure 14 compares the maximum heat transfer rate values of the instantaneous, time-averaged and steady data on the casing for different clearance heights and speeds. The area-averaged mean values are also depicted in Fig. 14. Figure 14 presents data for the casing only because its maximum heat transfer rate is relatively higher than the one observed on the blade tip surface. In Fig. 14a, it is evident that the maximum heat transfer rate decreases as the tip gap increases, however, the area-averaged Nusselt number slightly increases. For a given clearance height, the heat transfer rate is highest at a medium rotor speed (Fig. 14b). The instantaneous maximum Nusselt number is $21 \%$, $29 \%$ and $45 \%$ higher than the maximum of time averaged one for $0.6 \mathrm{~mm}, 1.2 \mathrm{~mm}$ and $2 \mathrm{~mm}$ gaps, respectively. At a medium speed, the instantaneous maximum heat transfer rate was observed to be $68 \%$ higher than the maximum of its time averaged distribution. The steady simulation could not capture this locally high value of heat transfer rate.

\section{Conclusions}

Unsteady simulations were performed to investigate time dependent behaviors of the leakage flow structures and heat transfer on the blade tip and casing in a single stage gas turbine. This paper mainly illustrates the unsteady nature of the tip leakage flow and heat transfer under the effect of the unsteady stator and rotor interactions. Firstly, the effects of various numbers of time steps, sub iterations and vane passing periods were tested for time-accurate prediction. The periodic nature of the tip leakage flow and heat transfer rate distribution with time is observed after

the $5^{\text {th }}$ vane passing. The effect of tip clearance height and rotor speed was also investigated. The major findings of this study could be summarized as follows:

- The stator flow structure, such as the compression wave is found to have a significant impact on the rotor flow and its heat transfer characteristics and contributes greatly to their unsteady nature.

- For any clearance height and a constant rotor speed, the tip leakage flow coverage is maximum when the pressure difference between the suction side and pressure side of the blade is highest as the compression wave from stator reaches the rotor surfaces.

- The same typical tip leakage flow structures and heat transfer rate distribution patterns are obtained in steady and unsteady time-averaged solutions. However, steady simulations seem to somewhat underpredict the heat transfer rate. On the other hand, the unsteady simulations, predict higher local and 
instantaneous heat transfer values. Thus, at a higher stage pressure ratio, the turbine designer is required to consider the unsteady characteristics of the flow and heat transfer.

- The turbine blade tip and casing undergo large heat transfer fluctuation (about $\mathrm{Nu}=2,000$ to 6,000 and about $\mathrm{Nu}=1,000$ to 10,000 , respectively) at a high frequency (coinciding with the rotor speed).

This study can be further extended by implementing some design methodologies for the turbine tip geometry configurations. In the present study, the inlet temperature was set to $444 \mathrm{~K}$ following the experimental work of Chana and Jones (2003). It is also recommended to extend this work further considering higher inlet temperature conditions, giving a more realistic representation of the turbine operating condition.

\section{References}

Chana, K. S., and Jones, T. V., “An Investigation on Turbine Tip and Shroud Heat Transfer,” Journal of Turbomachinery, Vol. 125, pp. 513-520, 2003.

De la Loma, A., Paniagua, G., Verrastro, D., and Adami, P., “Transonic Turbine Stage Heat Transfer Investigation in Presence of Strong Shock," ASME Turbo Expo 2007, GT2007-27101, 2007.

Denos, R.,Fidalgo, V. J. and Adami, P., "Transport of Unsteadiness across the Rotor of a Transonic Turbine Stage,” ASME Turbo Expo 2006, GT2006-90462, 2006.

Kim, S. I., Rahman, M. H. and Hassan, I., "Effect of turbine inlet temperature on rotor blade tip leakage flow and heat transfer," Int. Journal of Numerical Methods for Heat \& Fluid Flow, Vol. 22, No. 1, pp. 73-93, 2012.

Krishnababu, S. K., Newton, P. J., Dawes, W. N., Lock, G. D., Hodson, H. P., Hannis, J., and Whitney, C., “Aerothermal Investigations of Tip Leakage Flow In Axial Flow Turbines Part I: Effect of Tip Geometry and Tip Clearance Gap,” ASME Journal of Turbomachinery, Vol. 131, No. 1, 011006 (14 pages), 2009a.

Krishnababu, S. K., Dawes, W. N., Hodson, H. P., Lock, G. D., Hannis, J., and Whitney, C., “Aerothermal Investigations of Tip Leakage Flow In Axial Flow Turbines Part II: Effect of Relative Casing Motion,” ASME Journal of Turbomachinery, Vol. 131, No. 1, 011007 (10 pages), 2009b.

Metzger, D. E., Dunn, M. G., and Hah, C., “Turbine Tip and Shroud Heat Transfer”, Journal of Turbomachinery, Vol. 113, pp. 502-507, 1991.

Molter, S. M., Dunn, M., G., Haldeman, C., W., Bergholz, R., F., and Vitt, P., "Heat Flux Measurements and Predictions for the Blade Tip Region of A High Pressure Turbine,” ASME Turbo Expo 2006, GT2006-90048, 2006.

Palafox, P., Oldfield, M. L. G., Ireland, P. T., Jones, T. V. and La Graff, J. E., "Blade tip heat transfer and aerodynamic in a large scale turbine cascade with moving endwall," ASME Journal of Turbomachinery, Vol. 134, No. 2, 021020 (11 pages), 2012. 
Phutthavong, P., Hassan, I., and Lucas, T., “Unsteady Numerical Investigation of Blade Tip Leakage, Part 1: Time-Averaged Results," Journal of Thermophysics and Heat Transfer, Vol. 22, No. 3, pp. 464-473, 2008a.

Phutthavong, P., Hassan, I., and Lucas, T., "Unsteady Numerical Investigation of Blade Tip Leakage, Part 2: Time-Dependent Parametric Study," Journal of Thermophysics and Heat Transfer, Vol. 22, No. 3, pp. 474-484, 2008 b.

Polanka, M. D., Hoying, D. A., Meininger, M., and MacArthur, C. D., "Turbine Tip and Shroud Heat Transfer and Loading-Part A: Parameter Effects Including Reynolds Number, Pressure Ratio, and Gas-to-Metal Temperature Ratio," Journal of Turbomachinery, Vol. 125, pp.97-106, 2003.

Rahman, M. H., Kim. S. I, Hassan, I. and El Ayoubi, C., "Unsteady Tip Leakage Characteristics and Heat Transfer on Turbine Blade Tip and Casing," ASME Turbo Expo 2010, GT2010-22104, 2010.

Rahman, M. H., Kim. S. I, and Hassan, I., "Effects of Inlet Temperature Uniformity and Nonuniformity on the Tip Leakage Flow and Rotor Blade Tip and Casing Heat Transfer Characteristics,” ASME Journal of Turbomachinery, Vol. 134, No. 2, 021001 (10 pages), 2012.

Rahman, M. H., Kim. S. I, and Hassan, I., “Tip Leakage Flow and Heat Transfer on Turbine Blade Tip and Casing, Part 1: Effect of Tip Clearance Height and Rotation Speed," Int. Journal for Computational Methods in Engineering Science \& Mechanics, Vol. 14, No. 4, pp. 290-303, 2013.

Shyam, V., Ameri, A. and Chen, J. P., "Analysis of unsteady tip and endwall heat transfer in a highly loaded transonic turbine stage,” ASME Journal of Turbomachinery, Vol. 134, No. 4, 041022 (9 pages), 2012.

Thorpe, S. J., Yoshino, S., Thomas, G. A., Ainsworth, R. W., and Harvey, N. W., "Blade Tip Heat Transfer in a Transonic Turbine," Proceedings of the Institution of Mechanical Engineers, Part A: Journal of Power and Energy, Vol. 219, pp.421430,2005 .

Xie, Y., Lan, J., B., Fan, T., and Zhang, D., “An Investigation of Unsteady Aerodynamic load on Turbine Blade Considering Rotor-Stator Interactions" Proceedings of ISABE 2007, ISABE-2007-1257, 2007.

Yamamoto, A., Matsunuma, T., Ikeuchi, K., and Outa, E., "Unsteady Endwall/Tip-Clearance Flows and Losses Due to Turbine Rotor-Stator Interaction,” American Society of Mechanical Engineers (Paper), 94-GT-461, pp. 1-10, 1994.

Yang, D., Yu, X. and Feng, Z., "Investigation of leakage flow and heat transfer in a gas turbine blade tip with emphasis on the effect of rotation," ASME Journal of Turbomachinery, Vol. 132, No. 4, 041010 (9 pages), 2010. 
Table 1 Modeled turbine geometry and test conditions

\begin{tabular}{l|c|c}
\hline \hline & Baseline case & $\begin{array}{c}\text { Experiments } \\
\text { (Chana and Jones, 2003) }\end{array}$ \\
\hline Turbine inlet temperature, K & 444 & 444 \\
\hline Stator inlet total pressure, bar & 4.6 & 4.6 \\
\hline Rotor exit static pressure, bar & 1.43 & $\begin{array}{c}1.428 \text { (hub) } \\
1.435 \text { (casing) }\end{array}$ \\
\hline Rotor rotation speed, RPM & 9500 & 9500 \\
\hline Blade tip geometry & Flat tip & Flat tip \\
\hline Number of stator vanes & 30 & 32 \\
\hline Number of rotor blades & 60 & 60 \\
\hline \hline
\end{tabular}

Table 2 Test matrix of parametric study

\begin{tabular}{l|c|c|c}
\hline \hline \multicolumn{1}{c|}{ Test matrix } & Case number & $\begin{array}{c}\text { Tip clearance, } \mathrm{mm} \\
(\% \text { of blade span })\end{array}$ & Rotor speed, RPM \\
\hline \multirow{2}{*}{$\begin{array}{l}\text { Effect of tip clearance } \\
\text { height }\end{array}$} & Baseline & $1.2(3)$ & $9500(24 \%$ lower $)$ \\
\cline { 2 - 4 } & 1 & $0.6(1.5)$ & 9500 \\
\cline { 2 - 4 } $\begin{array}{l}\text { Effect of rotor rotation } \\
\text { speed }\end{array}$ & 2 & $2(5)$ & 9500 \\
\cline { 2 - 4 } & 3 & 1.2 & 12500 (design speed) \\
\hline \hline
\end{tabular}




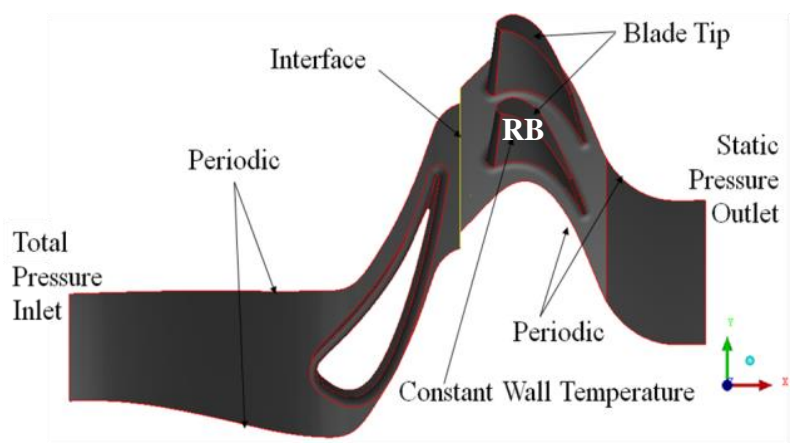

(a)

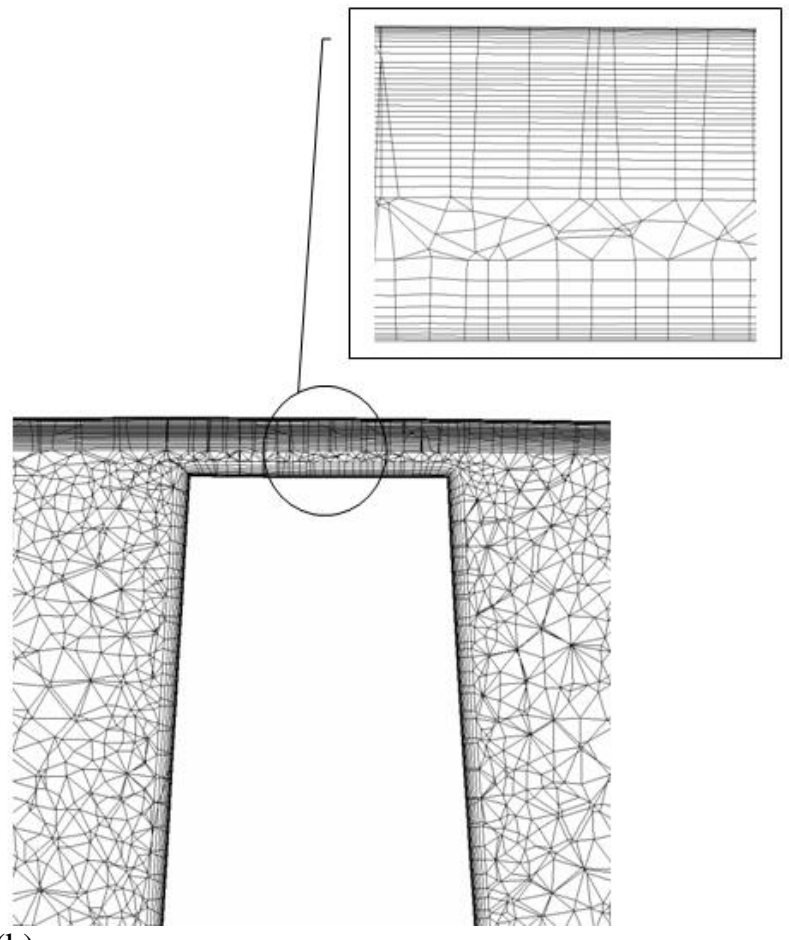

(b)

Figure 1. (a) Computational domain and (b) grid system in the rotor section. 

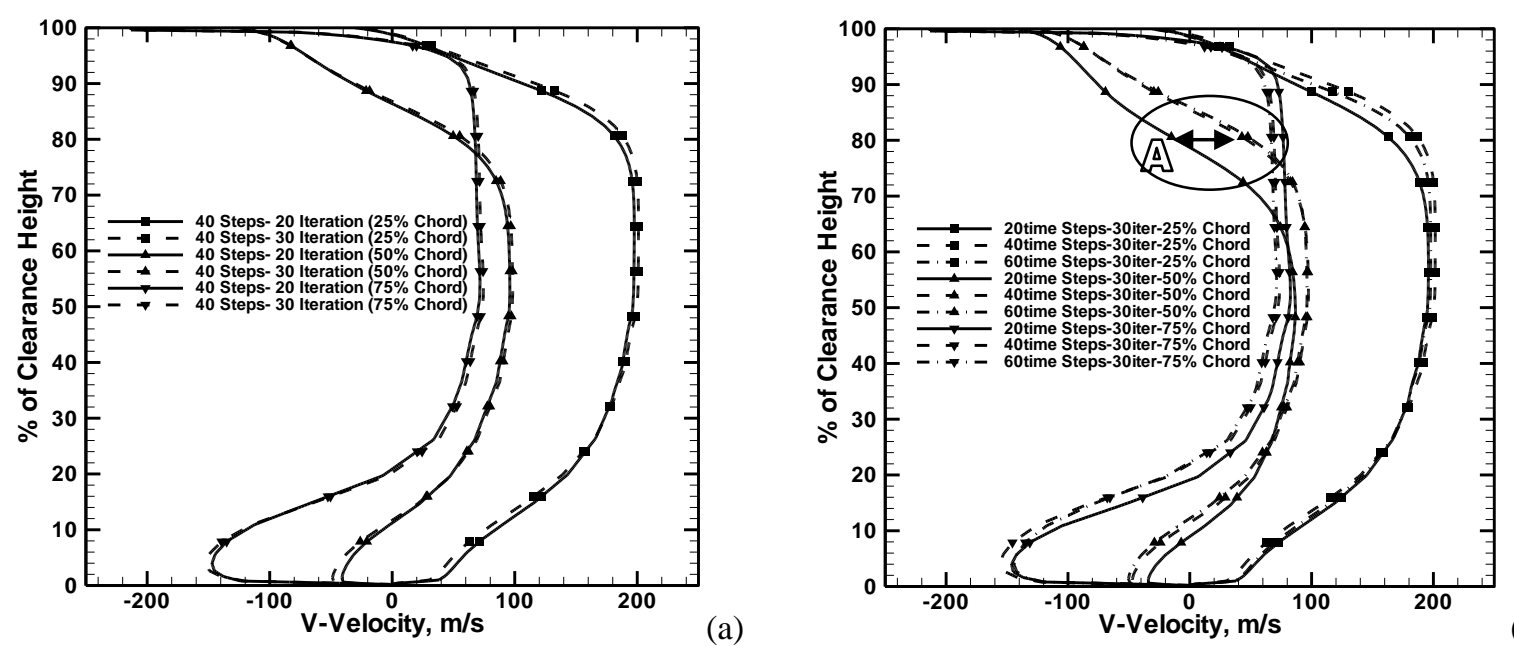

(b)

Figure 2. (a) number of Sub iterations, (b) time steps convergence for each time steps vane pass.

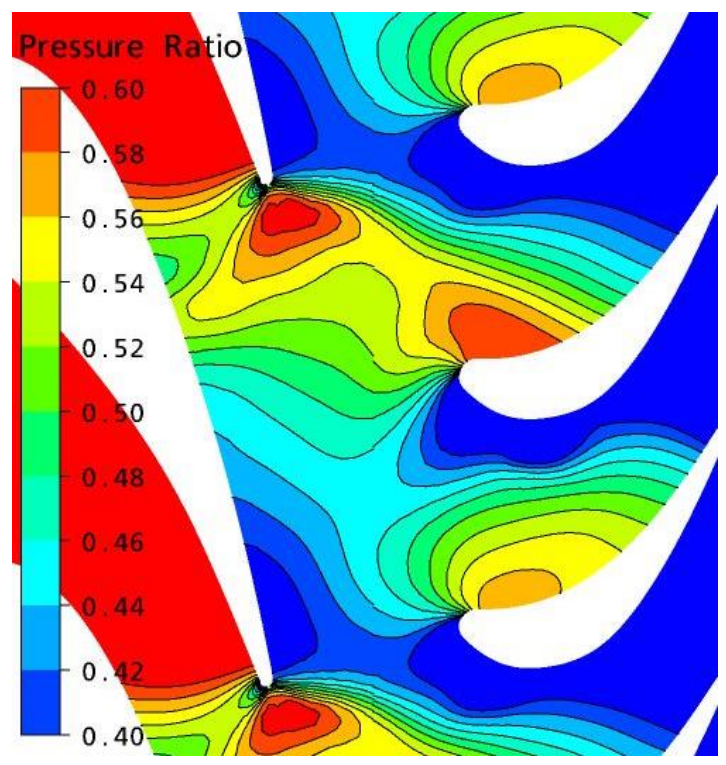

Figure 3. Instantaneous pressure ratio $\left(P / \mathbf{P}_{0, \text { in }}\right)$ contours at the $75 \%$ blade span (Baseline case, $\left.\mathrm{t}^{*}=4 / 8\right)$. 


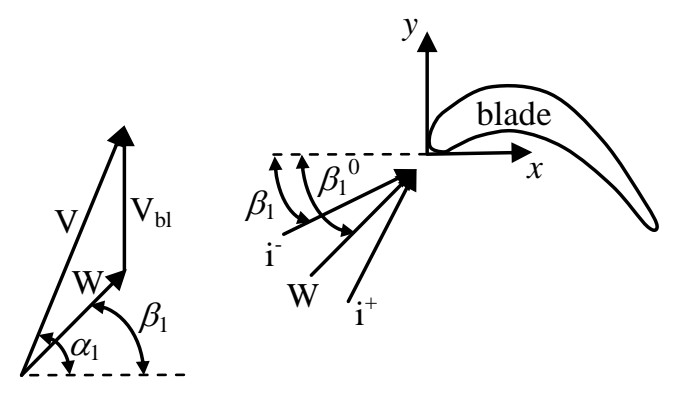

(a) Velocity triangle and incidence angle

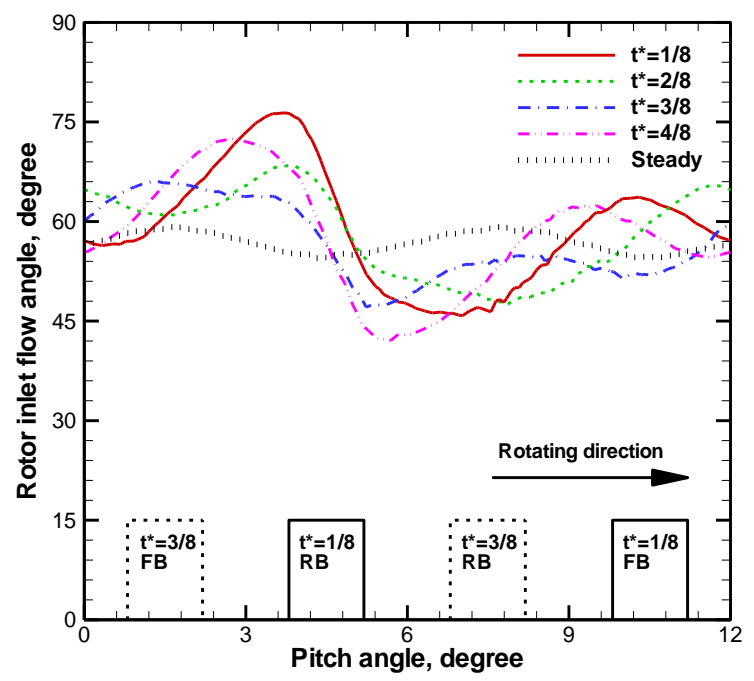

(b)

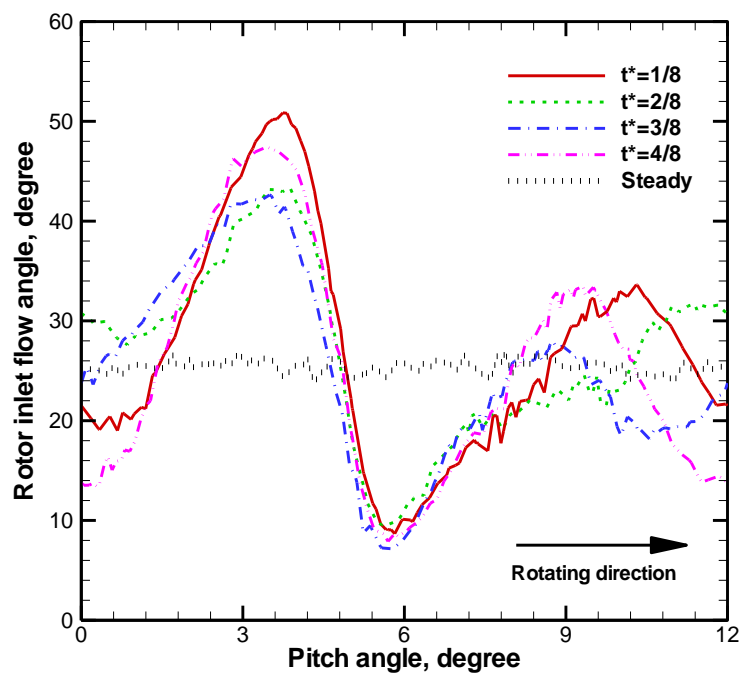

(c)

Figure 4. Inlet flow angle at mid tip clearance of the rotor side interface for one pitch along the circumference (b) Case: 9500 RPM; 1.2 mm; (c) Case: 12500 RPM; 1.2 mm. 


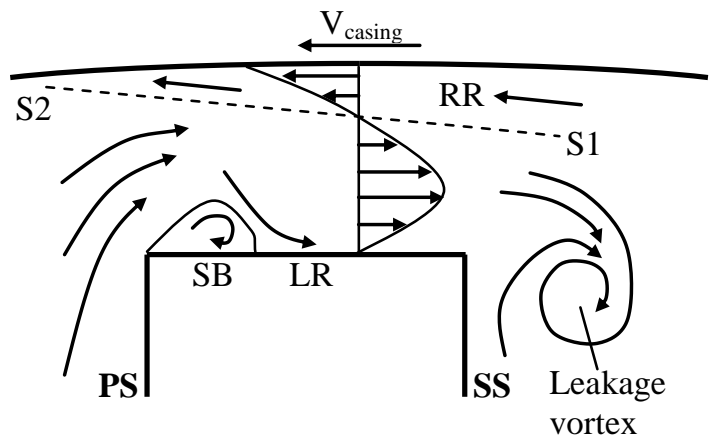

(a) Schematic of the typical tip leakage flow structure (flow observed from a rotating frame of reference)

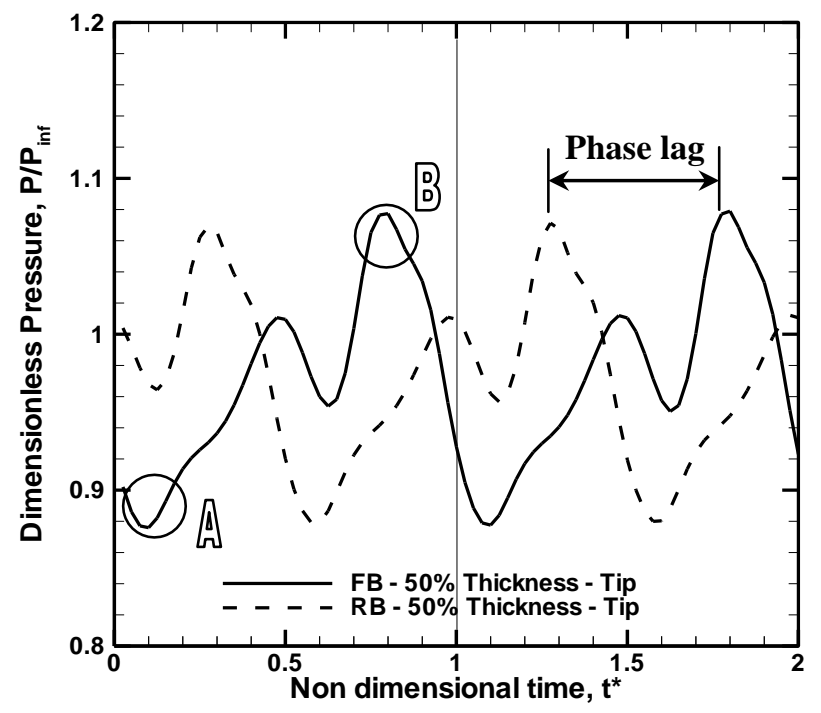

(b)

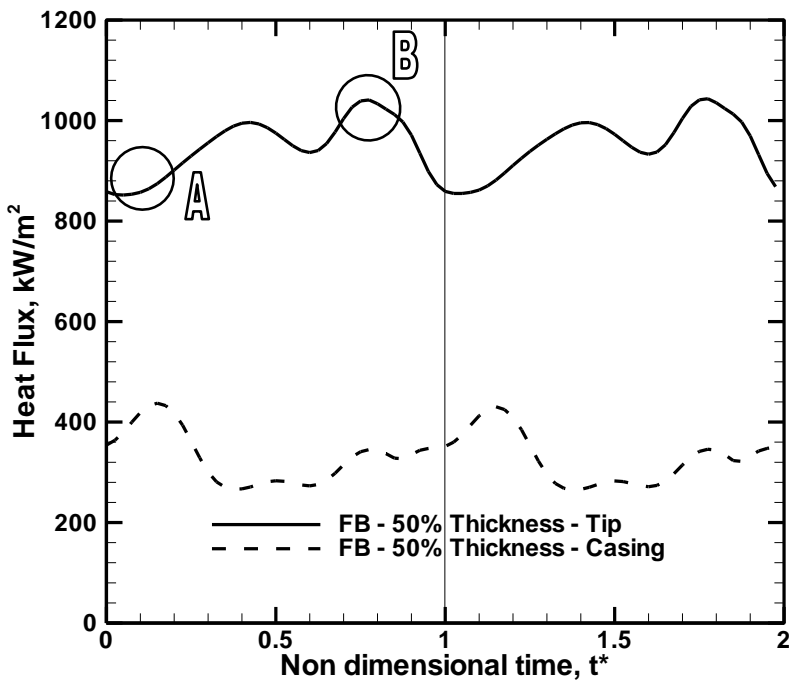

(c)

Figure 5. Pressure ratio (b) and heat flux (c) time histories inside the tip clearance at the quarter axial chord plane. (Case: 9500 RPM; $1.2 \mathrm{~mm}$ ) 


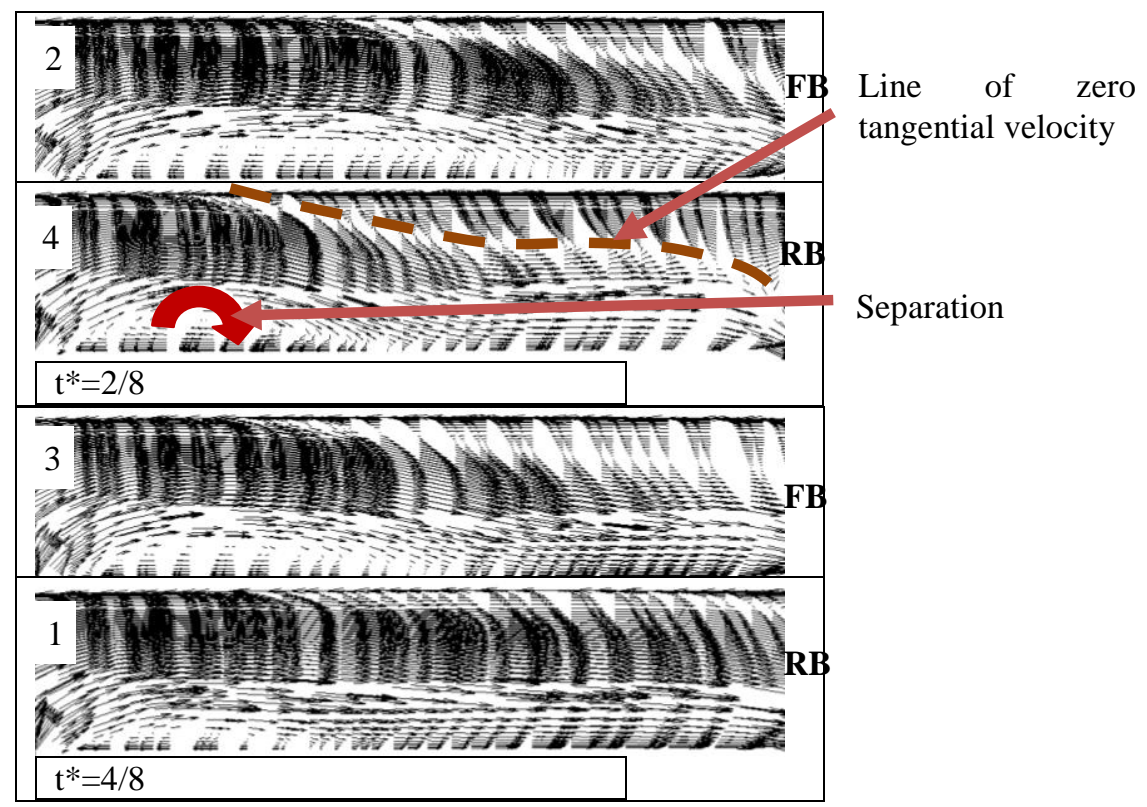

Figure 6. Velocity vectors at quarter axial chord plain for different clearance heights (baseline case).

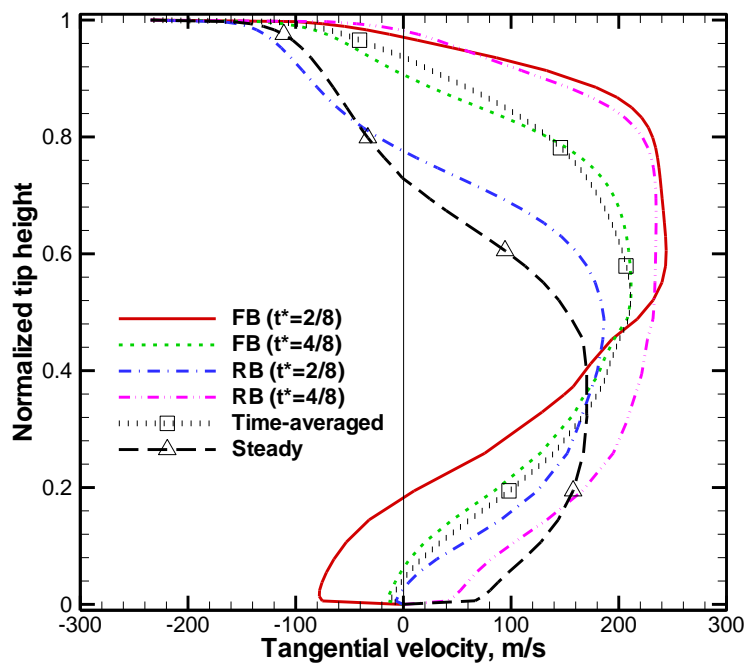

Figure 7. Tangential velocity profiles in the clearance region at $x / C_{x}=25 \% ; y / t_{y}=50 \%$ (Baseline case, 9500 RPM, $1.2 \mathrm{~mm})$. 


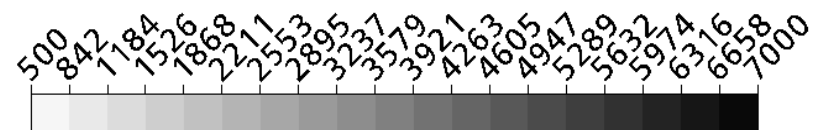

Nusselt Number
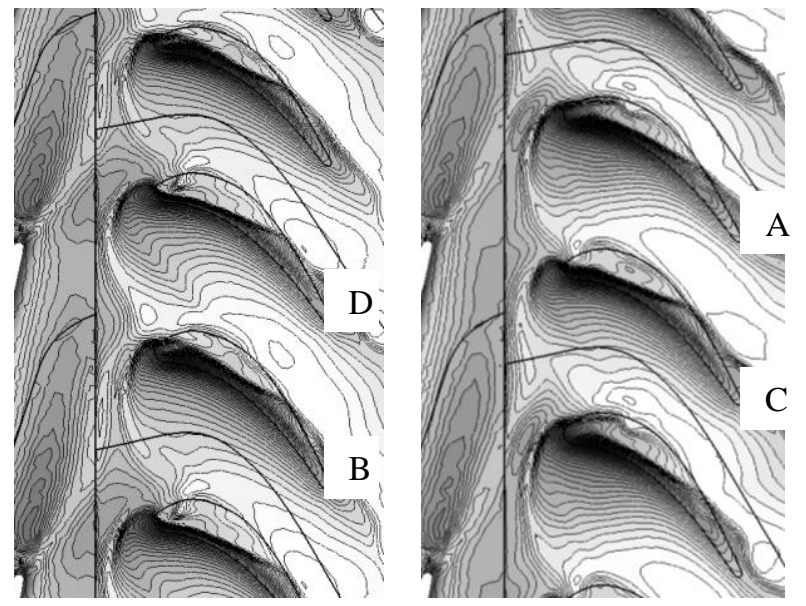

(a) $t^{*}=2 / 8$

(b) $t^{*}=4 / 8$
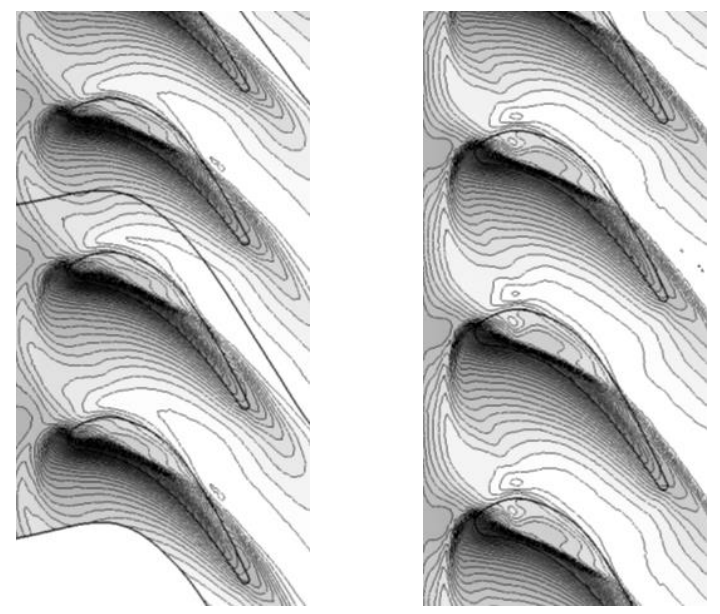

(c) Time average

(d) Steady

Figure 8. Nusselt number contours on the casing (Case: 9500 RPM; 1.2 mm). 


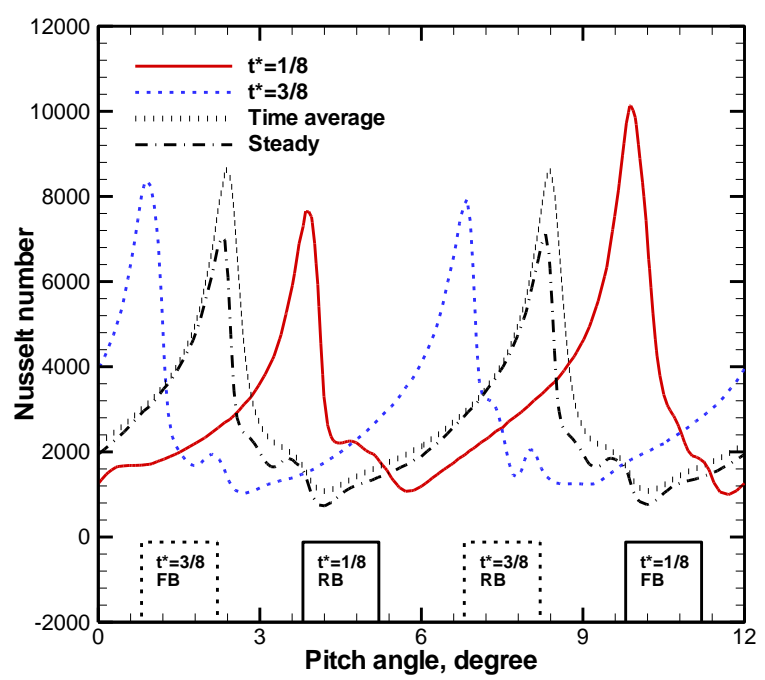

Figure 9. Nusselt number distributions along the casing circumference at the $25 \%$ axial chord (baseline case). 

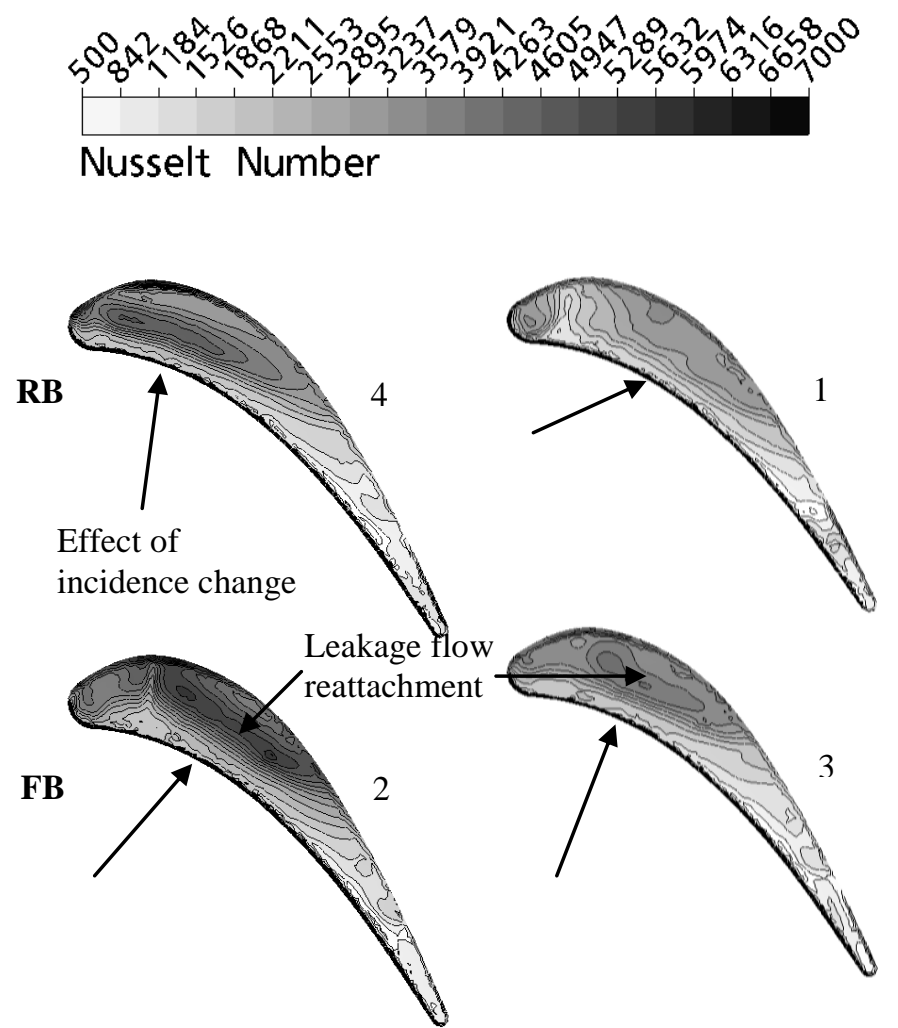
(a) $t^{*}=2 / 8$
(b) $t^{*}=4 / 8$
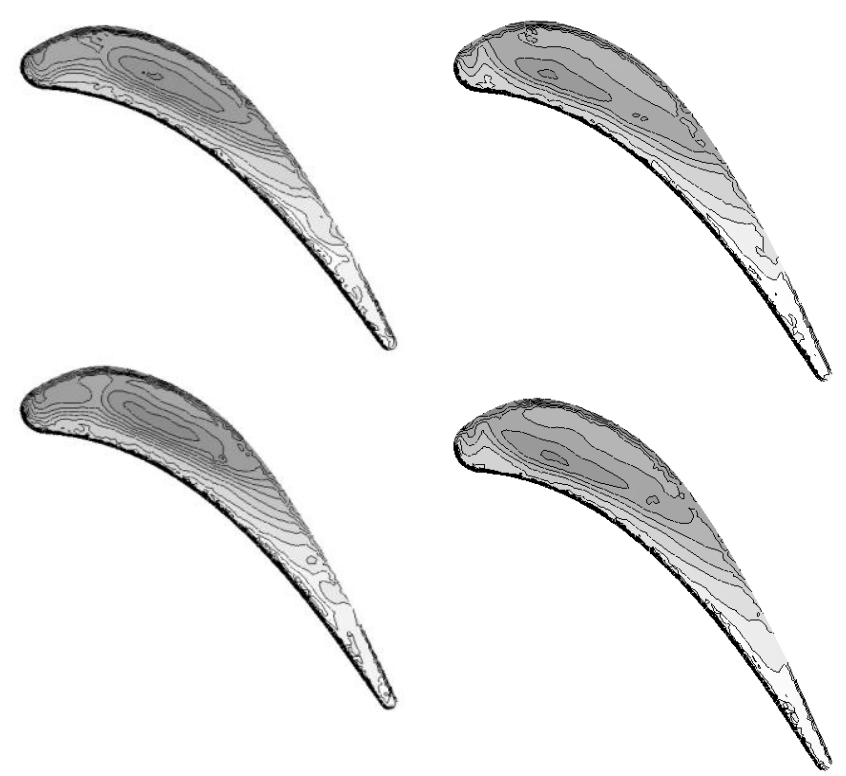

(c) Time average

(d) Steady

Figure 10. Nusselt number contours on the blade tip (Case: 9500 RPM; 1.2 mm). 


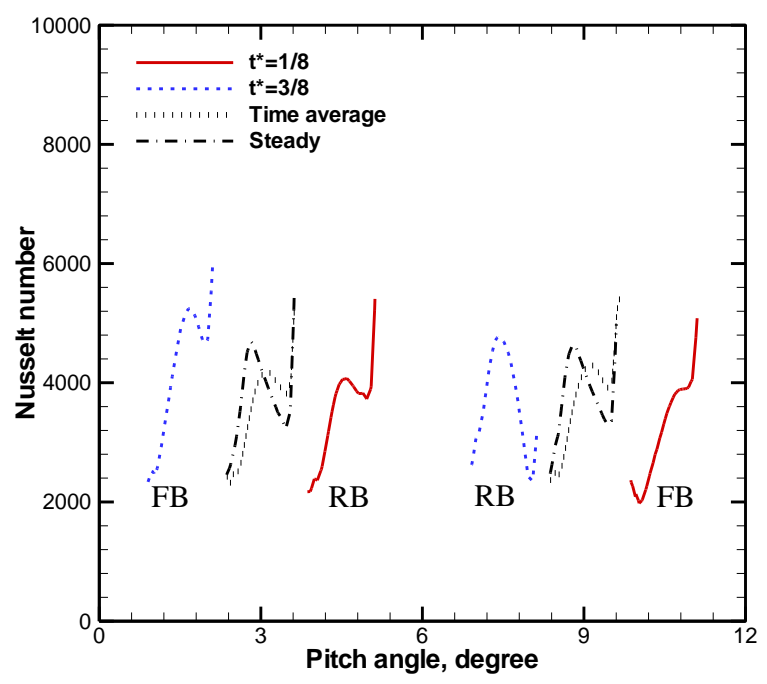

Figure 11. Nusselt number distributions on the blade tip surface at the $25 \%$ axial chord (baseline case).

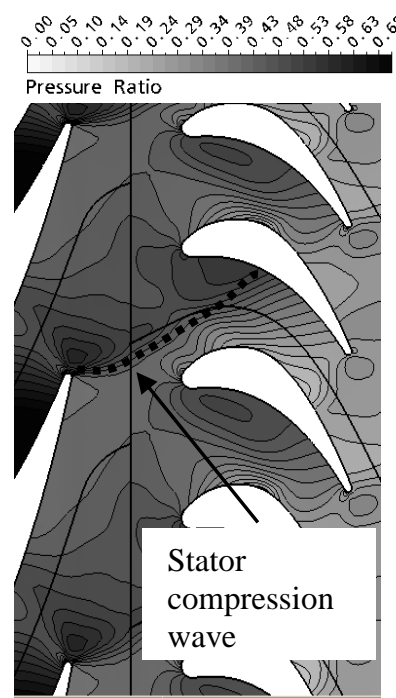

(a)

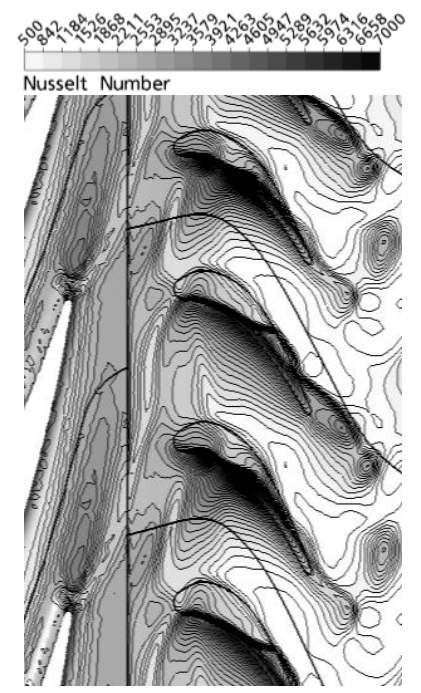

(b)

Figure 12. Contour of (a) pressure ratio at mid span and (b) Nusselt number on the rotor casing for the rotor speed of 12500 RPM $($ at $t *=1 / 8)$. 


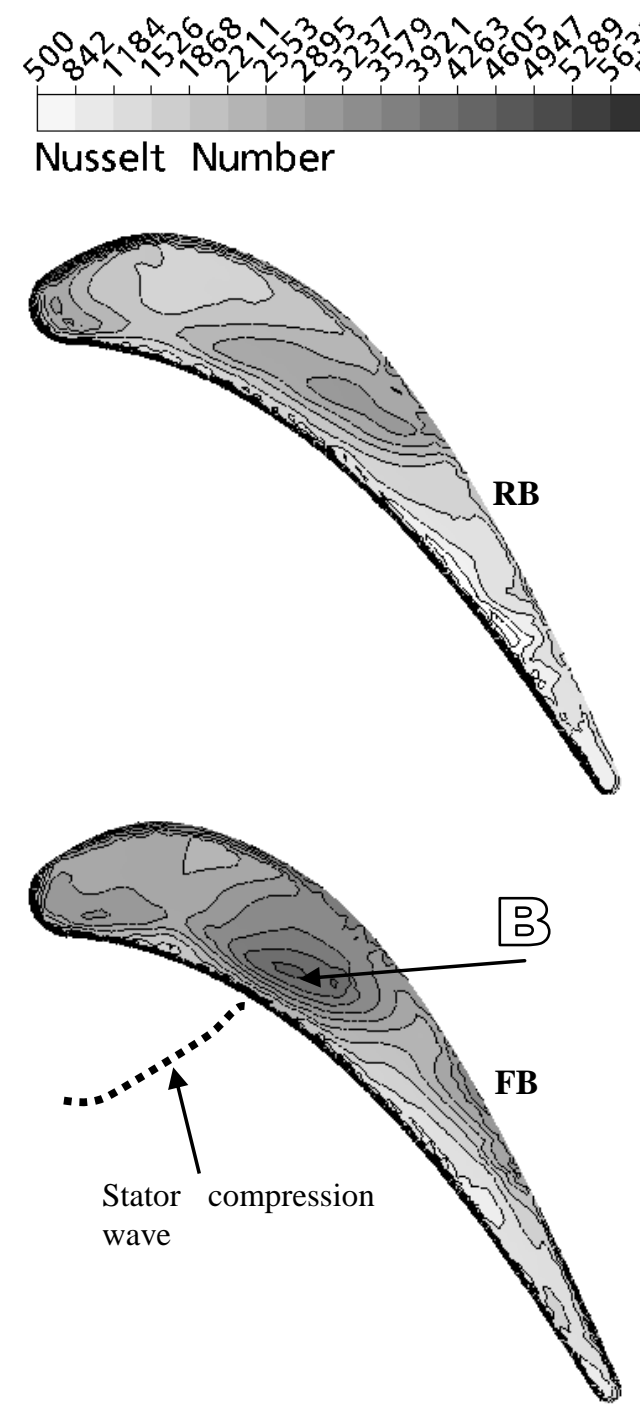

Figure 13. Contour of Nusselt number on the rotor blade tip for the rotor speed of 12500 RPM (at $\left.t^{*}=1 / 8\right)$. 


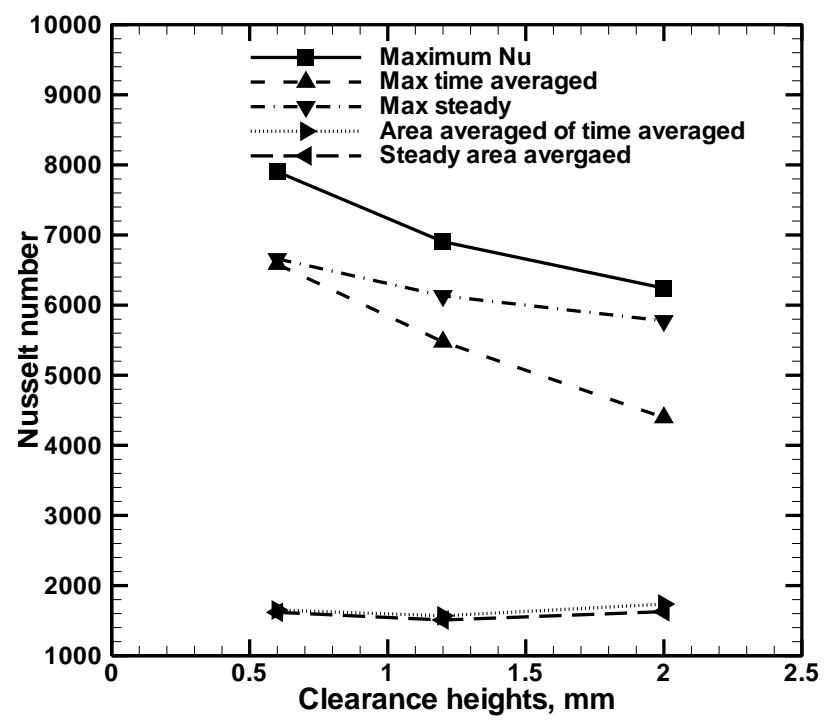

(a) 9500 RPM

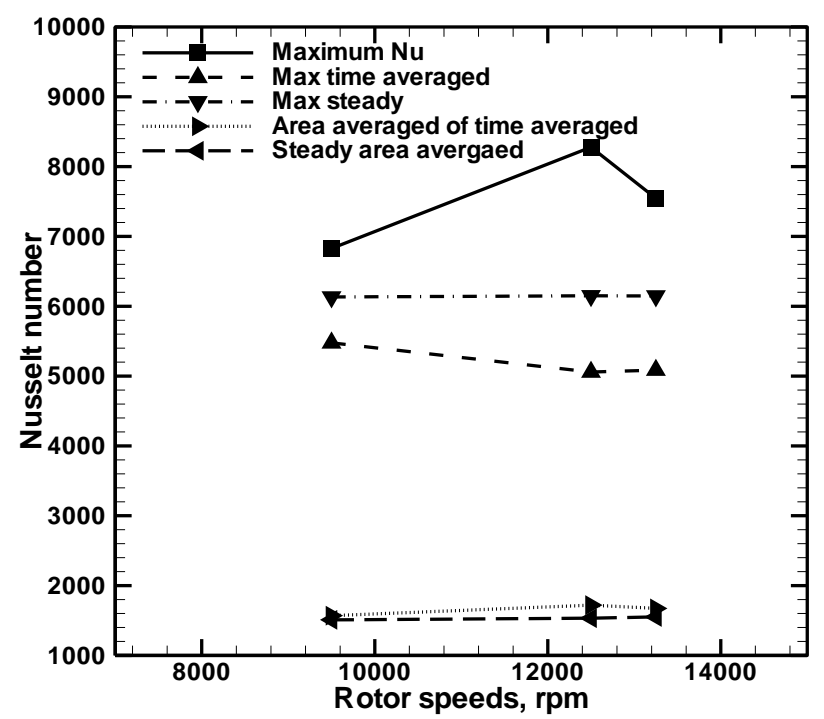

(b) $1.2 \mathrm{~mm}$

Figure 14. Comparison of critical heat transfer values on the casing for (a) clearance heights and (b) rotor speeds. 